\title{
Biological age vs. chronological age: the impact on the development of the young tennis athlete
}

\author{
André Vilela Brito
}

\section{ABSTRACT}

The aim of this paper is to understand how various factors such as maturation, peak height velocity, body growth and the effect of relative age can interfere with the athlete's development in sports and in personal terms. Studies indicate that athletes' development is made up of several stages of maturation, and it is likely that they may occur at different timings depending on the athlete, their birth date, their upbringing, and the type of practice they have undertaken. Thus, we will have to be aware of the prediction we make of an athlete's progression because this maturational timing influences both the physical and mental progression of the athlete. This is especially true given that evidence shows that those born in the first semester of the season or year may have early advantages over those born in the second semester. This may include finding ways to limit the ability to give more means and selection to teams or players that are stronger or more mature.

\author{
Key words: maturation, \\ chronological age, biological age, \\ development. \\ Received: 28 January 2020 \\ Accepted: 11 February 2020 \\ Corresponding author: André Vilela \\ Brito, Portugal. Email: \\ abritovilela@hotmail.com
}

\section{INTRODUCTION}

Recently, study on biological age has gained a significant amount of attention, and this in turn is due to the increasing scrutiny and analysis given to the study of factors affecting human and athlete performance. When we quantify biological age, we consider variables that may be important in determining the windows of opportunity for a particular component to develop.

Maturational biological age and chronological age are two important but different concepts. Chronological age is a probable index of the length of life a person has left, while biological age is the progression and direction to the state of maturity (Bacil, Junior, Rech, Legnani, and Campos, 2014).

Adolescence begins with puberty and ends when there is a cessation of skeletal growth, dental development and sexual maturation. This happens between 18 and 21 years old. Puberty is an unstable period, marked by body changes, where the peak height velocity ( $\mathrm{PHV}$ ) phenomenon is one of the most important aspects, along with the biological maturation of sexual organs, metabolic functions and gender differences (Bogin, 2011).

One of the most commonly used indicators for the investigation of maturation processes is and adolescent's
$\mathrm{PHV}$. This is a measure of the maximum growth rate in height during the growth phase (Gosselin-Despres, 2007).

The effect of relative age (ERA) " is the deviation of distribution of the selected athletes' birth dates from the normal distribution in the population. This means that means that the birth dates of selected groups of athletes are not distributed normally, i.e. approximately evenly throughout the whole year" (Zhanel, \& Hubacek, 2013, p. 27). This has been shown to be an influence on the athlete's development and training. Therefore, the use of the year of birth as a criterion to group different competitive categories has benefited young people born in the first months of each year (Junior, et al., 2013).

\section{METHOD}

This research conducted took the form of a systematic bibliographic review of scientific journal articles. The electronic databases searched were: Scielo; Google Scholar and Academy. Articles between 1993 and 2019 were searched using the following keywords: age; biological; chronological; young; and, athlete.

The keywords in the databases were introduced the evaluation of the titles and abstracts of each article was done following the following criteria: first, the population covered, if it was a young population, proceeded to the analysis of the type of restricting population of young people. practitioners and non-practitioners, for tennis players. 


\section{RESULTS AND DISCUSSION}

A considerable amount of tennis specific studies has been produced in this field. For clarification purposes, the articles will be summarised into two topics.

\section{Effect of relative age}

Agricola, Zhanel, \& Hubacek (2013) studied the influence of the effect of relative age on a population of junior tennis players aged 13-14 years old who participated in the ITF world junior tennis finals. They concluded that births of players fell into the first semester of the year more than $65 \%$ of the time for all years. In total $73.2 \%$ of the players were born in the first half of the year.

In a study to determine whether there was an effect of relative age on Swedish male and female junior tennis players born between 1998 and 2001, Gerdin, Hedberg and Hageskog (2018) found out that $52 \%$ of the Swedish population was born in the first half of the year, whereas $55 \%$ of the players ranked were born in the first half of the year. It was also observed that $60.2 \%$ of the top 50 ranked were born in the first half of the year. The authors concluded that there was an ERA when comparing the Swedish population with ranked players.

Another study by Ulbricht, Fernandez, Villanueva, \& Ferrauti (2015) tested the existence of ERA in young tennis players. They investigated whether the male players 11-17 years old selected went later on to national teams. The authors concluded that $65.1 \%$ of the players who played for the regional teams were born in the 1st half of the year and $34.9 \%$ in the 2 nd half, and as per the national team, $70.2 \%$ of the players were born in the 1 st half and $29.8 \%$ in the 2 nd half of the year.

Junior et al. (2014) studied the distribution of players, according to the relative age in the different age groups (U14, U16 and U18) with data from COSAT, ITF, ATP and WTA. They found a predominance of players who were born in the first semester of the year. In females, there were more players who willingly moved played in higher age groups. The greatest variation occurred in the males, reaching a difference of 51 months in the age group of $18 \& \mathrm{U}$. They concluded that there was an association between the effect of relative age and the ranking position in the age groups of $14 \& U$ and $18 \& U$.

The effect of relative age on the ranking of junior tennis players was investigated by Moreira, Lopes, Faria \& Albuquerque (2017) who further studied how "year" and "month" influence ranking. These authors found significant differences between birth quartiles. They concluded that there was a higher probability of athletes being born in the initial quartiles of the year than in the last quartile.
Loffing, Cobley \& Schorer (2010) studied whether left-handed players in tennis circumvent the ERA inequality. They found that ERA showed significant differences in right-handed, but in left-handed tennis players, no ERA was demonstrated. The highest percentage of right-handed players were born in the first semester while in left-handed players they showed an inverted trend, that is, in the second semester.

The occurrence of relative age in the $12 \& U, 14 \& U, 16 \& U$, $18 \& U$ and professional tennis categories of Brazilian (CBT), South American (COSAT) and international (ATP and ITF) players was investigated by Aoki, Moreira, Costa \& Massa (2014). They found significant differences between the expected birth distribution and the observed birth distribution. They concluded that, in most cases, there highest percentage of births occurred in the first quarter of each year, followed by the second highest percentage in the second quarter

\section{Development and maturity}

Parera Madruga et al. (2019) assessed and quantified the level of muscular asymmetry in limbs in chronological and maturational groups. Differences were found between the strongest and weakest limbs (between 3.5 and 5.5\%) in all groups but with larger asymmetries in the maturational groups. Asymmetries decreased with age and with the maturation level, with $12 \& U$ athletes showing higher values than $16 \& U$ athletes.

The effects of variations related to age and maturity on anthropometric characteristics, muscle strength and agility among young competitive athletes aged 10 to 13 years old were investigated by Sogut, et al. (2019). The authors found an effect for age on height, leg length and grip strength in favour of older players. In girls, results differed in most anthropometric measures due to the difference in maturation.

Kramer, Huijgen, Efenink-Gemser, Lyons \& Visscher (2019) investigated whether age, maturation or physical fitness in junior tennis players (U13) can explain the current state and future of tennis. They concluded that in the $13 \& U$ category, there were positive correlations between upper body power and tennis performance. In female players, there was a positive correlation between maturation, lower body power and performance in tennis. Players who matured earlier performed better, whereas late maturing players tended to perform well at $16 \& U$.

Somatic growth, sexual maturation and final height in female adolescent athletes (gymnasts, swimmers and tennis players) was compared by Erlandson, Sherar, Mirwald \& Maffulli (2008). They found that adolescent gymnasts reached menarche (the age at which menstruation starts) later and were shorter than swimmers and tennis players of the same age. There were no differences in height in adults.

A study to understand whether individual differences in growth and maturity can provide a performance advantage 
was conducted by Myburgh, Cumming, Coelho-e-Silva, \& Cooke (2016) with players aged 8-17 years old. They found that the average height and body mass of the players varied between the 50th and 90th percentiles for age and gender. Female athletes from the age of 8 had an advanced estimated bone age relative to chronological age. The study also observed that male 8-12-year-old athletes had average to delayed maturation (skeletal age to chronological age) but had advanced skeletal compared to chronological age from 14 to 16 year old categories.

Associations of physical characteristics, functional to the training of competitive under- 12 tennis players were examined by Sogut, Luz, Kaya, \& Altunsoy (2019). The authors found that in relation to boys, girls were significantly taller and more advanced in maturation. In girls, the percentage of adult height prediction was significantly correlated with ranking. Variables related to experience, training volume and motor performance were significantly associated with ranking in both girls and boys.

\section{CONCLUSIONS AND IMPLICATIONS}

As it has been shown, one of the many variables that directly affects the level of tennis is the effect of relative age, both in terms of classification and in the development process of the player as a selection.

The effect of relative age corresponds to the that that a child born in the early months of the early will have an advantage over the child born in the later months due to their maturity, thus a child born in January will tend to have an earlier maturation than a child who is born in December.

In morphological terms, the child born in January, will show higher stature, height and body weight indices which can cause increased strength, speed and power, aspects which are very important for the tennis.

Firstly, the way in which children are ranked may affect the dropout rate between children born in the same year where those born in the latter months of the year, and are thus less developed than their counterparts due to age differences, may be more likely to withdraw as the may feel that they cannot compete against their higher ranked peers.

Secondly, the selection process today is still too restrictive, utilising short-term selection variables. Therefore, if we have short-term variables in a selection process, the children who were born in the first trimester will be the most likely to be chosen, that is, those who demonstrate better strength, speed and power levels together with more height and Weight. Consequently, we will be giving priority to certain children and leaving others out.

In terms of relative age, the selection process should be considered more in the long term and not in the short term, as the child born in the last trimester will mature later and when maturing will be at least as well-developed than the child that matured early.

Given the physical and functional demands of tennis, biological age tends to play a fundamental role in the sport and in the athletes' performance and evolution. Size, strength and power are associated with advanced maturation, particularly during adolescence. These changes in body composition are associated with early or advanced maturity in females.

Finally, since tennis requires special attention in terms of using coordinative capacities and aerobic and anaerobic conditioning capacities, coaches should, as soon as possible, create a development plan in maturational terms for each athlete, which will respect the biological individuality of the person (Myburgh, Cumming, Coelho-e-Silva, \& Cooke, 2016).

\section{REFERENCES}

Aoki, M. S., Costa, E. C., \& Moreira, A. (2014). Efecto da idade relativa no Ténis. Revista Brasileira de Ciência e Movimento, 111-117, Aoki, M. S., Costa, E. C., \& Moreira, A. (2014). Efecto da idade relativa no Ténis. Revista Brasileira de Ciência e Movimento, 111-117. https://doi.org/10.18511/0103-1716/rbcm.v22n3p111117

Bacil, E. D. A., Júnior, O. M., Rech, C. R., dos Santos Legnani, R. F., \& de Campos, W. (2015). Atividade física e maturação biológica: uma revisão sistemática. Revista Paulista de Pediatria, 33(1), 114-121, https://doi.org/10.1016/j.rpped.2014.11.003

Bogin, B. (2011). Puberty and Adolescence: An Evolutionary Perspective. Encyclopedia of Adolescence, 275-286, https://doi.org/10.1016/B978-0-12-373951-3.00033-8

Erlandson, M. C., Sherar, L. B., Mirwald, R. L., Maffulli, N., \& Baxter-Jones, A. D. (2008). Growth and maturation of adolescent female gymnasts, swimmers, and tennis players. Medicine \& Science in Sports \& Exercise, 40(1), 34-42, https://doi.org/10.1249/mss.0b013e3181596678

Gerdin, G., Hedberg, M., \& Hageskog, C. A. (2018). Relative age effect in Swedish male and female tennis players born in 1998-2001. Sports, 6(2), 38, https://doi.org/10.3390/sports6020038

Gosselin-Despres, C. (2007, January). How to Measure Peak Height Velocity (PHV)? Retrieved from http://assets.ngin.com/attachments/document/0134/996 3/PHV.pdf

Júnior Ribeiro, E. J. F., Keller, B., Pereira, J. L., Coelho, R. W., Boas, V., Silva, M., \& Grunevald, E. (2013). O fenômeno da idade relativa em atletas de tênis infantojuvenil e profissional: nível de associação com o ranking da federação sul-americana e mundial. Revista da Educação Física/UEM, 24(3), 371-379.

Kramer, T., Huijgen, B., Elferink-Gemser, M. T., Lyons, J., \& Visscher, C. (2010). Physical development of young talented tennis players. Parte: http://hdl. handle. net/10316.2/2676, https://doi.org/10.14195/978-98926-0506-7 7 
Loffing, F., Schorer, J., \& Cobley, S. P. (2010). Relative Age Effects are a developmental problem in tennis: but not necessarily when you're left-handed!. High Ability Studies, 21(1), 19-25, https://doi.org/10.1080/13598139.2010.488084

Moreira, J. P. A., Lopes, M. C., Faria, L. O., \& Albuquerque, M. R. (2017). Relative age effect and constituent year effect: an analysis of the international tennis federation ranking. Journal of Physical Education, 28, https://doi.org/10.4025/jphyseduc.v28i1.2814

Myburgh, G. K., Cumming, S. P., Coelho E Silva, M., Cooke, K., \& Malina, R. M. (2016). Growth and maturity status of elite British junior tennis players. Journal of sports sciences, 34(20), 1957-1964, https://doi.org/10.1080/02640414.2016.1149213

Myburgh, G. K., Cumming, S. P., Silva, M. C. E., Cooke, K., \& Malina, R. M. (2016). Maturity-associated variation in functional characteristics of elite youth tennis players. Pediatric exercise science, 28(4), 542-552, https://doi.org/10.1123/pes.2016-0035

Madruga-Parera, M., Romero-Rodríguez, D., Bishop, C., Beltran-Valls, M. R., Latinjak, A. T., Beato, M., \& FortVanmeerhaeghe, A. (2019). Effects of maturation on lower limb neuromuscular asymmetries in elite youth tennis players. Sports, 7(5), 106, https://doi.org/10.3390/sports7050106

Rosenbloom, A. L. (2007). Physiology of growth. Annales Nestlé (English ed.), 65(3), 97-108, https://doi.org/10.1159/000112232

Söğüt, M., Luz, L. G., Kaya, Ö. B., Altunsoy, K., Doğan, A. A., Kirazci, S., ... \& Knechtle, B. (2019). Age-and MaturityRelated Variations in Morphology, Body Composition, and Motor Fitness among Young Female Tennis Players. International journal of environmental research and public health, 16(13), 2412, https://doi.org/10.3390/ijerph16132412

Ulbricht, A., Fernandez-Fernandez, J., Mendez-Villanueva, A., $\&$ Ferrauti, A. (2015). The relative age effect and physical fitness characteristics in German male tennis players. Journal of sports science \& medicine, 14(3), 634

Zháněl, J., \& Hubáček, O. (2013). Relative age effect in junior tennis (male). Acta Gymnica, 43(1), 27-33, https://doi.org/10.5507/ag.2013.003
RECOMMENDED ITF TENNIS ACADEMY CONTENT (CLICK BELOW)

\section{TTF Academy}

Copyright (c) 2020 André Vilela Brito

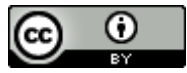

This text is under a Creative Commons BY 4.0 license

\begin{abstract}
You are free to Share - copy and redistribute the material in any medium or format - and Adapt the content - remix, transform, and build upon the material for any purpose, even commercially under the following terms:
\end{abstract}

Attribution: You must give appropriate credit, provide a link to the license, and indicate if changes were made. You may do so in any reasonable manner, but not in any way that suggests the licensor endorses you or your use.

CCBY 4.0 license terms summary CCBY4.0 license terms 